\title{
Antenatal Care Attendance and Factors Influenced Birth Weight of Babies Born between June 2017 and May 2018 in the Wa East District, Ghana
}

\author{
Prince Kubi Appiah (D, ${ }^{1,2}$ Mohammed Bukari, ${ }^{3}$ Simon Nidoolah Yiri-Erong, ${ }^{4}$ \\ Kwabena Owusu, ${ }^{5}$ George Borogyante Atanga, ${ }^{6}$ Stephen Nimirkpen, \\ Blaise Bagyliku Kuubabongnaa, ${ }^{3}$ and Martin Adjuik ${ }^{8}$ \\ ${ }^{1}$ Department of Family and Community Health, School of Public Health, University of Health and Allied Sciences, Ho, Ghana \\ ${ }^{2}$ Department of Medical Law and Ethics, Asian Institute for Bioethics and Health Law, College of Medicine, Yonsei University, \\ Seoul, Republic of Korea \\ ${ }^{3}$ Health Information Unit, District Health Administration, Ghana Health Service, Wa East District, Upper West Region, Ghana \\ ${ }^{4}$ Department of Public Health and Community Medicine, Institute of Medicine, University of Gothenburg, Sweden \\ ${ }^{5}$ Health Information Unit, District Health Administration, Ghana Health Service, Wa West District, Upper West Region, Ghana \\ ${ }^{6}$ Health Information Unit, District Health Administration, Ghana Health Service, Sissaala West District, Upper West Region, Ghana \\ ${ }^{7}$ Health Information Unit, Municipal Health Administration, Ghana Health Service, Lawra Municipal, Upper West Region, Ghana \\ ${ }^{8}$ Department of Epidemiology and Biostatistics, School of Public Health, University of Health and Allied Sciences, Ho, Ghana
}

Correspondence should be addressed to Prince Kubi Appiah; appiahkubiprince23@yahoo.com

Received 25 February 2020; Revised 18 June 2020; Accepted 29 June 2020; Published 20 July 2020

Academic Editor: Robert Gaspar

Copyright (c) 2020 Prince Kubi Appiah et al. This is an open access article distributed under the Creative Commons Attribution License, which permits unrestricted use, distribution, and reproduction in any medium, provided the original work is properly cited.

Background. In sub-Saharan Africa, there is high coverage of the recommended four or more times antenatal care (ANC) visits during pregnancy without complications; notwithstanding this achievement, the negative birth outcomes related to childbirth such as low birth weights and stillbirths are still high despite the increased access to antenatal services. Hence, the study assessed the association between antenatal attendance and birth weight in the Wa East District. Method. The cross-sectional study design was used with a semistructured questionnaire to collect data from mothers who delivered within a one-year period through a review of antenatal and birth records from health facilities where the women delivered and interviewed. The chi-squared test and univariate and multivariate logistic regression were performed to establish the association between normal birth weight and ANC services the woman received and other predictor variables, and $p$ value $<0.05$ was considered a significant association between dependent and independent variables. Result. The study involved 233 women. About $62.2 \%$ attended ANC clinics $4+$ times before giving birth, $70.0 \%$ did not received the minimum ANC services required for every pregnant woman, $0.9 \%$ of pregnancies resulted in stillbirth, and $24.5 \%$ of babies born had a birth weight $<2.5 \mathrm{~kg}$. Women marital status (legally married) [AOR: 2.05, 95\% CI: 1.33-6.89, $p=0.044$ ], religion (Islam) [AOR: 0.33, 95\% CI: 0.08-0.39, $p=0.013$ ], and educational level (SHS/tertiary) [AOR: 4.27, 95\% CI: $0.08-0.88, p=0.031$ ] were the background characteristics associated with normal birth weight $(2.5-40 \mathrm{~kg})$. Also, women who had their urine tested at the ANC clinics [AOR: 6.59, 95\% CI: 8.48-15.07, $p<0.001$ ] and women who received a long-lasting insecticide-treated net [AOR: 2.17, 95\% CI: 0.03-0.92, $p=0.039$ ] from the ANC clinic were associated with normal birth weight. Conclusion. Notwithstanding the benefits of antenatal care services, only $62.2 \%$ of pregnant women attended 4 or more ANC visits before giving birth, while $70 \%$ did not received the services they need. These might have influence the $24.5 \%$ of babies born with a low birth weight. Therefore, there is a need for special attention from all stakeholders to reverse the trend. 


\section{Introduction}

Antenatal care (ANC) is a fundamental component of routine maternal and child health services and provides opportunities for many different services to be offered to pregnant mothers with the aim of screening and detecting danger signs early and providing the necessary timely interventions. The goal of antenatal care is to reduce maternal and child mortality and morbidity; for example, the roll-out of antimalarial drugs and antiretroviral therapy for maternal HIV/AIDS are services offered at antenatal care sessions to reduce maternal and child morbidity and mortality [1]. Therefore, frequent visits to the ANC clinic are crucial in realizing the full benefits of ANC services. Antenatal services such as tetanus toxoid-diphtheria vaccination, IPTp for malaria control, and HIV prevention of mother-to-child transmission (PMTCT) depend on several visits and the trimester in which they occur to be effective [2].

Pregnant women stand a greater risk of losing their lives or their babies if proper care and attention are not given to them during antenatal care until delivery. Globally, in 2015, the maternal mortality ratio was estimated to be around 216 per 100,000 live births and occurring mostly in lowresource settings [3] due to pregnancy-related causes [4] while skilled attendance at birth coverage in 2013 was estimated to have reached $73 \%$; however, more than $40 \%$ of births in WHO Africa Region were not attended to by a skilled health personnel [5]. Also, globally, an estimated 5.9 million children in less than 5 years lost their lives in 2015, with neonatal and under-five mortality rates of 19 per 1,000 live births and 42.5 per 1,000 live births, respectively, occurring; however, the highest mortality occurred in sub-Saharan Africa, where antenatal care (4+ visits) in 2015 was 55\% [6]. It is also known that good quality of care at childbirth can produce a triple effect on any investment made, saves mothers and newborns, and prevents stillbirths and low birth weights. Therefore, the provision of effective care for all women and babies during birth in health facilities could prevent about 113,000 maternal deaths; 531,000 stillbirths; and 1.3 million neonatal deaths that occurred annually by 2020 [6]. Yet, about half of the under-five deaths are caused by malaria, tetanus, measles, sepsis, pneumonia, and AIDS which are directly associated with the lack or insufficient antenatal care services [7].

In Ghana, the maternal mortality ratio is estimated at $310 / 100,000$ live births, while neonatal and infant mortality rates were $25 / 1,000$ and $37 / 1,000$ pregnancies [8], respectively. Also, the Ghana Demographic and Health Survey estimates ANC coverage at $97.3 \%$, ANC $4+$ visits at $82.9 \%$, and low birth weight at 9.5\% [9]. In particular, the Wa East District has seen some improvement over the years in ANC coverage from $84.6 \%$ in 2017 to $85.8 \%$ in 2019 , while ANC 4+ visits increased from $70.7 \%$ in 2017 to $71.9 \%$ in 2019 . With the consistent increase of ANC coverage and significant coverage of the 4th visit, it was expected that the negative birth outcomes such as stillbirths and low birth weights would have been reduced to the minimum levels. But, the district recorded an increase in the low birth weight rate from $6.2 \%$ in 2017 to $7.5 \%$ in 2019 , which could be a contributory factor to neonatal deaths and increased in stillbirths from 5 per 1,000 pregnancies in 2017 to 15 per 1,000 pregnancies in 2019 [10]. Although the district is yet to fall above the national ANC coverage (80\%) and ANC 4+ visits (78\%) targets, the increase in stillbirth and low birth weight rates amidst the increased ANC coverage and ANC 4+ visits suggests an investigation; hence, the study examined the association between antenatal care attendance and birth outcomes among mothers who delivered from June 2017 to May 2018 in the Wa East District.

\section{Materials and Methods}

2.1. Study Site. The Wa East District is a complete rural district with 145 communities. Currently, the district has an estimated population of about 87,182 with a $3.9 \%$ fertility rate. There are 9 health centres, a health post/clinic, and 28 functional community-based health planning and service (CHPS) facilities in the district rendering health services to the people. Although there are no hospitals and polyclinics in the district, the health centres there possess the needed resources and the potentials to render the basic emergency obstetrics and newborn care (EmONC) services to whoever needs these services [10].

2.2. Study Population. The study population includes women aged 15 to 45 years, who attended ANC clinics and delivered in health facilities in the district between June 2017 and May 2018. However, women who went through a caesarean section before delivery were excluded from the study because a study has shown that babies delivered through a caesarean section may gain more weight due to the fluids given to the mother before and during surgery [11]. Also, women with missing ANC and delivery data from health facility records, health professionals, and foreign nationals were excluded from the study.

2.3. Study Design. A descriptive cross-sectional design was employed to collect the study data at one point in time. The study involved reviewing individual records of women who gave birth at a health facility between June 2017 and May 2018 and interviewed the women for additional information. Variables that data were collected in the facility include parity, number of ANC visits made before delivery, birth weight of the child, still/live birth, and a minimum amount of ANC services received by mothers before delivery. Data collected from the mothers directly include the mothers' demographic data and counselling information given to mothers during ANC visits. Mothers' ANC booklets were referred to as where necessary to ascertain the needed information.

2.4. Sample Size. The sample size of two hundred and thirtythree (233) participants involved in the study was determined using the Cochran formulated formula for crosssectional population-based studies: $n=z^{2} \times p(q) / d^{2}$ [12], where $n$ was the sample size to be determined, $z$ was the $z$ -score of the area under the standard normal curve corresponding to the desired confidence level of 95\% (1.96), $p$ was the prevalence of low birth weight of $16.5 \%(0.165)$ in the population [13], $q$ was $1-p$, and $d$ was the $5 \%(0.005)$ 
acceptable margin of error. Considering a $10 \%$ nonresponse rate for the 212 participants, the sample size, finally became 233 participants. This was to ensure that the estimated prevalence fell within $\pm 5 \%$ of the true population coverage, with a probability of $95 \%$.

2.5. Sampling Method. Nine health centres were providing basic emergency obstetrics and newborn care (EmONC) services in the district. Hence, we purposively selected all the nine health centres for the study, and a probability proportionate to the size sampling method was used to allocate the sample size to each health centre based on the total deliveries conducted between $1^{\text {st }}$ June 2017 and $31^{\text {st }}$ May 2018. After getting the sample size for the health centres, the number of deliveries registered in each health centre's delivery register became a sample frame, and a systematic sampling method was used to select the number of women allocated to the health centre. The selected women were traced to their homes using the contact information in their health records.

2.6. Data Collection Tools and Procedure. A semistructured questionnaire was used for data collection, and pretesting of the tool was done using five (5) women who were not part of the study participants to ensure that it addressed all the objectives without ambiguity. Four nurses who were familiar with ANC activities and services were recruited from outside the study area, and were trained to collect data for the study, and were persons who understood the local dialect and could explain the questionnaire to the understanding of the study participants using the three main languages in the area, namely, Dagaare, Sisaali, and Chakali. The participants were interviewed, and their ANC and delivery records were reviewed. Information collected includes age, educational level, religion, parity, gestational age at first ANC visit, number of ANC visits, child's birth weight, livebirth, stillbirth, and counselling during ANC visits.

2.7. Data Analysis. The analytical software STATA version 13.1 was used for data analysis, and frequencies and proportions were used to report on ANC attendance, minimum ANC services received, and other variables. The minimum ANC service received was determined using the following fourteen services provided to pregnant women during an antenatal care visit: measured weight, height, blood pressure, and hemoglobin level; assessed gestational age; performed urine, syphilis, and PMTCT tests; gave iron-folic acid supplementation, tetanus-diphtheria injection, sulphadoxinepyrimethamine (SP) tablets, and LLIN; and counselled on nutrition and family planning services. Mothers who received 13 or less of these services were classified as getting below the minimum requirements. The chi-squared and logistics regression tests were performed to determine the association between independent and dependent variables. The $p$ value $<0.05$ was considered statistically significant.

\section{Results}

3.1. Background Characteristics of Participants. A total of 233 women who attended ANC clinics and delivered in health facilities in the district were interviewed and health records reviewed with more than half $148(63.5 \%)$ of them being within the ages of 20 to 34 years and a mean age of 27 years \pm 7.0 standard deviation. Majority 215 (92.3\%) of them were legally married and as high as $113(48.5 \%)$ of the women have no formal education while only $17(7.3 \%)$ have secondary and tertiary education. More than half 149 (64.0\%) of them were farmers, and 53 (22.7\%) were unemployed. Islamic religion $167(71.7 \%)$ was the major form of religious expression in the district. About 56 (24.0\%) of the women had delivered four or more children before the current child, while 99 $(42.5 \%)$ and $78(33.5 \%)$ of the women had delivered 1 and 2-3 times before the current child they have (Table 1).

3.2. Antenatal Services Women Received. About 145 (62.2\%) of the women attended four or more ANC clinics for care while $12(5.2 \%)$ went to ANC clinics only once. All the women had their weight and height measured, and blood pressure checked. Also, about 229 (98.3\%) received ironfolic supplementation of which 84 (36.7\%) and $100(43.7 \%)$ had it four and five or more times, respectively, 161 (69.1\%) were given sulphadoxine-pyrimethamine (SP) tablets out of which 107 (66.5\%) got it twice, 202 (86.7) got tetanusdiphtheria vaccination, and $171(73.4 \%)$ received a longlasting insecticide-treated net (LLITN). Again, 230 (98.7\%) were tested against PMTCT, $204(87.6 \%)$ had their urine tested and 228 (97.9\%) tested for syphilis, and 222 (95.3\%) had their hemoglobin levels checked, while 231 (99.1\%) had gestational age checked, and 223 (95.7\%) and 230 (98.7\%) received counselling on family planning and nutrition, respectively. Generally, only $30.0 \%$ of the women received all the 14 minimum services required (Table 2).

\subsection{Pregnancy Outcome and Birth Weight. About 2 (0.9\%)} out of the 233 pregnancies resulted in stillbirth (Figure 1(a)), while 57 (24.5\%) of the babies born had birth weight below $2.5 \mathrm{~kg}$ (abnormal) (Figure 1(b)).

3.4. Associations between Background Characteristics and Normal Birth Weight. The chi-squared analysis showed significant associations between birth weight and marital status $(p=0.04)$, religion $(p=0.016)$, and educational level $(p=0.003)$ of the women. To further confirm the associations, bivariate logistic analysis was performed, and it was confirmed and showed associations between normal birth weight and legally married women [COR: 2.71, 95\% CI: 1.01-7.24, $p=0.047$ ], women who were Muslims [COR: $0.39,95 \%$ CI: $0.18-0.85, p=0.018]$, and women who have attained secondary/tertiary education [COR: 3.15, 95\% CI: $0.04-0.61, p=0.008]$. The associations indicated that married women were 2.7 times more likely to give birth to children with a normal birth weight than women who were in cohabitation relationships, women who were Muslims were $61 \%$ less likely to deliver babies with a normal birth weight than those who were Christians, while women with secondary/tertiary education were about 3.2 times more likely to give birth to children with a normal birth weight than women with no education.

Furthermore, when variables that were having associations with normal birth weight from the bivariate analysis 
TABLE 1: Background characteristics of participants.

\begin{tabular}{lccc}
\hline Variable & & Frequency & Percentage \\
\hline \multirow{3}{*}{ Age group (years) } & $<20$ & 41 & 17.6 \\
& $\geq 35$ & 148 & 63.5 \\
Marital status & Legally married & 215 & 18.9 \\
& Cohabitation & 18 & 92.3 \\
Religion & Christianity & 66 & 28.7 \\
& Islam & 167 & 71.7 \\
Occupation & Unemployed & 53 & 22.7 \\
& Farmer & 149 & 64.0 \\
& Trader & 31 & 13.3 \\
Educational level & No education & 113 & 48.5 \\
& Primary/JHS & 103 & 44.2 \\
& SHS/tertiary & 17 & 7.3 \\
Parity & $0-1$ & 99 & 42.5 \\
& $2-3$ & 78 & 33.5 \\
\hline
\end{tabular}

were tested for confounding effects using multiple logistic regression analysis, it was further confirmed that women who are legally married [AOR: 2.05, 95\% CI: 1.33-6.89, $p=0.044$ ], women who were Muslims [AOR: 0.33, 95\% CI: $0.08-0.39, p=0.013]$, and women who have attained secondary/tertiary education [AOR: 4.27, 95\% CI: 0.08$0.88, p=0.031]$ were associated with normal birth weight. This also indicated that legally married women were about 2.1 times more likely to give birth to children with a normal birth weight than women who are in cohabitation relationships, women who were Muslims were 67\% less likely to deliver babies with a normal birth weight than those who were Christians, while women who have attained secondary/tertiary education were 4.3 times more likely to give birth to babies with a normal birth weight than women who had no education (Table 3).

3.5. Associations between Antenatal Services the Woman Received and Normal Birth Weight. Again, chi-squared analysis showed significant associations between the birth weight and checking of hemoglobin levels $(p=0.002)$, urine test $(p=0.000)$, times sulphadoxine-pyrimethamine (SP) tablets received $(p=0.018)$, syphilis test $(p=0.003)$, LLITN distribution $(p=0.002)$, counsel on FP $(p=0.008)$, counsel on nutrition $(p=0.013)$, and birth outcome $(p=0.013)$.

To further confirmed the associations, a bivariate logistic analysis was performed, and this confirmed and showed associations between a normal birth weight and women who had their hemoglobin levels tested [COR: 6.02, 95\% CI: $1.69-21.39, p=0.006]$, women who had their urine tested [COR: 15.18, 95\% CI: 6.23-8.28, $p<0.001$ ], women who received SP tablets 2 times [COR: 1.37, 95\% CI: 0.16$0.86, p=0.021]$, women who were tested for syphilis [COR: 3.21, 95\% CI: $1.45-2.73, p=0.022$ ], women who received LLITN [COR: 3.26, 95\% CI: 0.11-0.65, $p=0.004$ ], and women who were counselled on FP [COR: 5.06,
95\% CI: $1.37-8.62, p=0.015]$. The associations indicated that women who had their hemoglobin levels checked were 6 times more likely to give birth to children with a normal birth weight than women whose hemoglobin levels were not tested, women who had their urine tested were 15.2 times more likely to deliver babies with a normal birth weight than those without urine test, women who received SP tablets 2 times were about 1.4 times more likely to give birth to children with a normal birth weight than women who received SP once, women who were tested for syphilis were 3.2 times more likely to give birth to babies with a normal birth weight than those who were not tested, and women who received LLITN were also 3.3 times more likely to deliver babies with a normal birth weight than those who were not given, while women who were counseled on FP were 5.1 times more likely to deliver children with a normal birth weight than those who were not counseled.

Additionally, when variables that were having associations with normal birth weight from the bivariate analysis were tested for confounding effects using multiple logistic regression analysis, it was confirmed that women who had their urine tested [AOR: 6.59, 95\% CI: 8.48-15.07, $p<0.001$ ] and women who received LLITN [AOR: 2.17, 95\% CI: $0.03-0.92, p=0.039$ ] were associated with normal birth weight. This indicated that women who had their urine tested and women who received LLITN were 6.6 and 2.2 times more likely to give birth to babies with a normal birth weight than women whose urine were not tested and those who did not receive LLITN, respectively (Table 4).

\section{Discussion}

Almost half (48.5\%) of the mothers in Wa East District never went to school. Meanwhile, decreasing levels of education has been linked to lower birth weight [14]. Again, maternal educational level is known to influence child health as well as reducing unhealthy behaviours, including smoking $[15,16]$. Mothers who are employed and work characteristics have been associated with reduced low birth weight [17], yet the present study showed that $22.7 \%$ of mothers are unemployed. Another study in Nigeria also indicated that higher maternal education and occupation were associated with higher mean birth weights and showed that low birth weight was higher among mothers in the lower social class compared with mothers in the upper social class [18]. About $7.7 \%$ of mothers in the current study were involved in cohabiting relationships. Meanwhile, a study has shown that mothers who were not married are associated with an increased risk of low birth weight [19]. Though a study has shown that advancing in maternal age enhances birth weight by influencing foetal growth, $17.6 \%$ of mothers in the present study were below 20 years of age [20].

Globally, pregnant women are to make at least four or more antenatal care visits from skilled personnel before giving birth [21]. However, only $62.2 \%$ of mothers in the present study made four or more ANC visits, which is far below the $80 \%$ target set for all districts to achieve and Ghana's demographics and health survey $[9,22]$. Contrary, the Nigeria and 
TABLE 2: Antenatal services women received.

\begin{tabular}{|c|c|c|c|}
\hline Variable & & Frequency & Percentage \\
\hline \multirow{3}{*}{ Number of ANC visits } & $0-1$ & 12 & 5.2 \\
\hline & $2-3$ & 76 & 32.6 \\
\hline & $4+$ & 145 & 62.2 \\
\hline \multirow{2}{*}{ Gestational age determined } & No & 2 & 0.9 \\
\hline & Yes & 231 & 99.1 \\
\hline \multirow{2}{*}{ Height taken } & No & 0 & 0.0 \\
\hline & Yes & 233 & 100.0 \\
\hline \multirow{2}{*}{ PMTCT tested } & No & 3 & 1.3 \\
\hline & Yes & 230 & 98.7 \\
\hline \multirow{2}{*}{ Iron-folic acid supplementation given } & No & 4 & 1.7 \\
\hline & Yes & 229 & 98.3 \\
\hline \multirow{3}{*}{ Times folic acid received $(n=229)$} & $1-2$ & 45 & 19.6 \\
\hline & $3-4$ & 100 & 43.7 \\
\hline & $5+$ & 84 & 36.7 \\
\hline \multirow{2}{*}{ Hemoglobin level checked } & No & 11 & 4.7 \\
\hline & Yes & 222 & 95.3 \\
\hline \multirow{2}{*}{ Urine tested } & No & 29 & 12.4 \\
\hline & Yes & 204 & 87.6 \\
\hline \multirow{2}{*}{ Tetanus-toxoid vaccination received } & No & 31 & 13.3 \\
\hline & Yes & 202 & 86.7 \\
\hline \multirow{2}{*}{ Weight taken } & No & 0 & 0.0 \\
\hline & Yes & 233 & 100.0 \\
\hline \multirow{2}{*}{$\mathrm{SP}$ tablets received } & No & 72 & 30.9 \\
\hline & Yes & 161 & 69.1 \\
\hline \multirow{2}{*}{ Times SP tablets received $(n=161)$} & 1 & 54 & 33.5 \\
\hline & 2 & 107 & 66.5 \\
\hline \multirow{2}{*}{ Syphilis tested } & No & 5 & 2.1 \\
\hline & Yes & 228 & 97.9 \\
\hline \multirow{2}{*}{ LLITN received } & No & 62 & 26.6 \\
\hline & Yes & 171 & 73.4 \\
\hline \multirow{2}{*}{ Counselled on FP } & No & 10 & 4.3 \\
\hline & Yes & 223 & 95.7 \\
\hline \multirow{2}{*}{ Counselled on nutrition } & No & 3 & 1.3 \\
\hline & Yes & 230 & 98.7 \\
\hline \multirow{2}{*}{ Blood pressure checked } & No & 0 & 0.0 \\
\hline & Yes & 233 & 100.0 \\
\hline \multirow{2}{*}{ Received minimum ANC service } & No & 163 & 70.0 \\
\hline & Yes & 70 & 30.0 \\
\hline
\end{tabular}

Eastern Sudan studies reported lower proportions (54\% and $11 \%$, respectively) [23, 24]. Admittedly, a cross-sectional study in Kumasi, Ghana, indicated the lack of ANC attendance to the fact that mothers were not sick and so there was no need to visit ANC clinics or hospitals, as well as cultural beliefs [25]. These could also be the reasons why mothers in the Wa East District were not attending ANC clinics, although why mothers were not attending ANC clinics were not captured in the present study. The minimum ANC package in the study refers to the 14 services outlined in Table 2 in Results of the paper which are provided for preg- nant mothers at the ANC clinic. However, the study revealed that only $30 \%$ of the mothers received all ANC services required. Partly, the pregnant women who were unable to attend the recommended four or more visits could not have received all services. Again, in a rural district such as $\mathrm{Wa}$ East, where there are no laboratory facilities, services such as urine test and hemoglobin checks are not readily offered. Therefore, pregnant women are usually requested to visit another district for these services to be rendered. As a result, some mothers find it inconvenient and may not adhere to the referral and hence did not receive all the services that every 


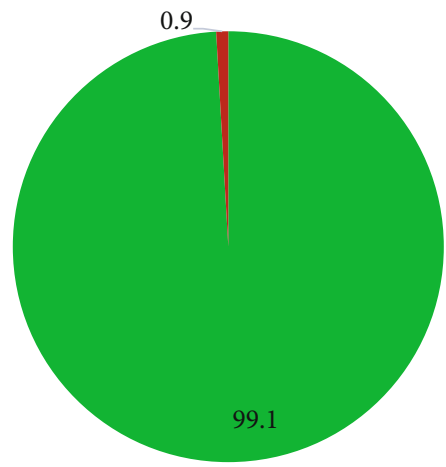

Livebirth

Stillbirth

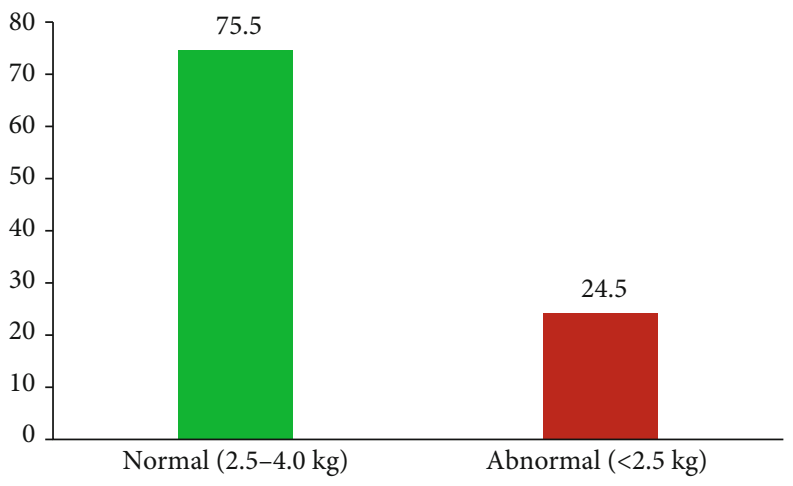

Livebirth

Stillbirth

(b) Birth weight of children

(a) Pregnancy outcome

FIGURe 1: (a) Pregnancy outcome. (b) Birth weight of children.

TABLE 3: Associations between background characteristics and a normal birth weight.

\begin{tabular}{|c|c|c|c|c|c|c|}
\hline \multirow[b]{2}{*}{ Variable } & \multicolumn{2}{|c|}{ Birth weight } & \multicolumn{2}{|c|}{ Pearson $\mathrm{chi}^{2}$} & \multirow[b]{2}{*}{ COR $(95 \%$ CI); $p$ value } & \multirow[b]{2}{*}{ AOR (95\% CI); $p$ value } \\
\hline & $\begin{array}{c}\text { Normal }(2.5-4.0 \mathrm{~kg}) \\
n=176(\%)\end{array}$ & $\begin{array}{c}\text { Abnormal }(<2.5 \mathrm{~kg}) \\
n=57(\%)\end{array}$ & $\mathrm{Chi}^{2}$ & $p$ value & & \\
\hline \multicolumn{7}{|l|}{ Age group (years) } \\
\hline$<20$ & $33(80.5)$ & $8(19.5)$ & \multirow{3}{*}{1.160} & \multirow{3}{*}{0.560} & 1 & \\
\hline $20-34$ & $112(75.7)$ & $36(24.3)$ & & & $0.75(0.32-1.78) ; 0.520$ & \\
\hline$\geq 35$ & $31(70.5)$ & $13(29.5)$ & & & $0.58(0.21-1.58) ; 0.287$ & \\
\hline \multicolumn{7}{|l|}{ Marital status } \\
\hline Cohabitation & $10(55.6)$ & $8(44.4)$ & \multirow{2}{*}{4.215} & \multirow{2}{*}{0.040} & 1 & 1 \\
\hline Legal married & $166(77.2)$ & $49(22.8)$ & & & $2.71(1.01-7.24) ; 0.047$ & 2.05 (1.33-6.89); 0.044 \\
\hline \multicolumn{7}{|l|}{ Religion } \\
\hline Christianity & $57(86.4)$ & $9(13.6)$ & \multirow{2}{*}{5.842} & \multirow{2}{*}{0.016} & 1 & 1 \\
\hline Islam & $119(71.3)$ & $48(28.7)$ & & & $0.39(0.18-0.85) ; 0.018$ & $0.33(0.08-0.39) ; 0.013$ \\
\hline \multicolumn{7}{|l|}{ Occupation } \\
\hline Farmer & $115(77.2)$ & $34(22.8)$ & \multirow{3}{*}{0.671} & \multirow{3}{*}{0.715} & 1 & \\
\hline Trader & $23(74.2)$ & $8(25.8)$ & & & $0.85(0.35-2.07) ; 0.721$ & \\
\hline Unemployed & $38(71.7)$ & $15(28.3)$ & & & 0.75 (0.37-1.52); 0.425 & \\
\hline \multicolumn{7}{|l|}{ Educational level } \\
\hline No education & $84(74.3)$ & $29(25.7)$ & \multirow{3}{*}{11.919} & \multirow{3}{*}{0.003} & 1 & 1 \\
\hline Primary/JHS & $82(79.6)$ & $21(20.4)$ & & & 1.35 (0.71-2.55); 0.359 & $1.20(0.12-2.14) ; 0.876$ \\
\hline SHS/tertiary & $10(58.8)$ & $7(41.2)$ & & & 3.15 (0.04-0.61); 0.008 & $4.27(0.08-0.88) ; 0.031$ \\
\hline \multicolumn{7}{|l|}{ Parity } \\
\hline $0-1$ & $78(78.8)$ & $21(21.2)$ & \multirow{3}{*}{1.6789} & \multirow{3}{*}{0.432} & 1 & \\
\hline $2-3$ & $55(70.5)$ & $23(29.5)$ & & & $0.64(0.33-1.28) ; 0.208$ & \\
\hline $4+$ & $43(76.8)$ & $13(23.2)$ & & & 0.89 (0.41-1.95); 0.772 & \\
\hline
\end{tabular}

pregnant woman is required. Also, shortages of logistics, such as iron-folic acid tablets, long-lasting insecticide-treated nets, sulphadoxine-pyrimethamine tablets, and HIV and syphilis test kits, mean that mothers who attended ANC clinics at the times of shortages were denied such services. Hence, most pregnant women did not receive ANC services required. Nonetheless, a comparative cross-sectional study in northern
Ghana made a similar finding and indicated that only $34.6 \%$ of mothers received adequate ANC care services [26]. Again, a study conducted in Bangladesh reported a lower proportion $(22 \%)$ of mothers who received all the prescribed ANC services [27]. The Bangladesh study also revealed that mothers who received the minimum ANC service were about 2.4 times more likely to give birth to children with a normal birth 
TABLE 4: Associations between antenatal services woman received and normal birth weight.

\begin{tabular}{|c|c|c|c|c|c|c|}
\hline \multirow[b]{2}{*}{ Variable } & \multicolumn{2}{|c|}{ Birth weight } & \multicolumn{2}{|c|}{ Pearson $\mathrm{chi}^{2}$} & \multirow[b]{2}{*}{ COR (95\% CI); $p$ value } & \multirow[b]{2}{*}{ AOR (95\% CI); $p$ value } \\
\hline & $\begin{array}{c}\text { Normal }(2.5-4.0 \mathrm{~kg}) \\
\quad n=176(\%)\end{array}$ & $\begin{array}{c}\text { Abnormal }(<2.5 \mathrm{~kg}) \\
n=57(\%)\end{array}$ & $\mathrm{Chi}^{2}$ & $p$ value & & \\
\hline \multicolumn{7}{|c|}{ Number of ANC visits } \\
\hline $0-1$ & $11(91.7)$ & $1(8.3)$ & \multirow{3}{*}{4.255} & \multirow{3}{*}{0.235} & 1 & \\
\hline $2-3$ & $61(80.3)$ & $15(19.7)$ & & & $0.31(0.04-2.69) ; 0.288$ & \\
\hline $4+$ & $104(71.7)$ & $41(28.3)$ & & & $0.23(0.03-1.84) ; 0.167$ & \\
\hline \multicolumn{7}{|c|}{ Gestational age determined } \\
\hline Yes & $176(76.2)$ & $55(23.8)$ & \multirow{2}{*}{3.101} & \multirow{2}{*}{0.078} & & \\
\hline No & $0(0.0)$ & $2(100)$ & & & Omitted & \\
\hline \multicolumn{7}{|c|}{ PMTCT tested } \\
\hline Yes & $176(76.5)$ & $54(23.5)$ & \multirow{2}{*}{3.214} & \multirow{2}{*}{0.073} & & \\
\hline No & $0(0.0)$ & $3(100)$ & & & Omitted & \\
\hline \multicolumn{7}{|c|}{ Iron-folic acid supplementation given } \\
\hline Yes & $172(75.1)$ & $57(24.9)$ & \multirow{2}{*}{1.318} & \multirow{2}{*}{0.251} & & \\
\hline No & $4(100)$ & $0(0.0)$ & & & Omitted & \\
\hline \multicolumn{7}{|c|}{ Times folic acid received $(n=229)$} \\
\hline $1-2$ & $39(86.7)$ & $6(13.3)$ & \multirow{3}{*}{3.209} & \multirow{3}{*}{0.201} & 1 & \\
\hline $3-4$ & $74(74.0)$ & $26(26.0)$ & & & 0.47 (0.18-1.26); 0.133 & \\
\hline $5+$ & $60(71.4)$ & $24(28.6)$ & & & $0.42(0.16-1.12) ; 0.082$ & \\
\hline \multicolumn{7}{|c|}{ Hemoglobin level checked } \\
\hline No & $4(36.4)$ & $7(63.6)$ & \multirow{2}{*}{9.587} & \multirow{2}{*}{0.002} & 1 & 1 \\
\hline Yes & $172(77.5)$ & $50(22.5)$ & & & 6.02 (1.69-2.14); 0.006 & $0.15(0.01-2.27) ; 0.17$ \\
\hline Urine test & & & & & & \\
\hline No & $7(24.1)$ & $22(75.9)$ & 47,353 & $<0.001$ & 1 & 1 \\
\hline Yes & $169(82.8)$ & $35(17.2)$ & & $<0.001$ & $5.18(6.23-8.28) ;<0.001$ & $6.59(8.48-15.07) ;<0.001$ \\
\hline Tetanus- $\mathrm{t}$ & vaccination received & & & & & \\
\hline No & $23(74.2)$ & $8(25.8)$ & 0082 & 0775 & 1 & \\
\hline Yes & $153(75.7)$ & $49(24.3)$ & 0.002 & 0.17 & $1.14(0.48-2.71) ; 0.775$ & \\
\hline SP tablets & ved & & & & & \\
\hline No & $59(81.9)$ & $13(18.1)$ & 2315 & 0128 & 1 & \\
\hline Yes & $117(72.7)$ & $44(27.3)$ & 2.515 & 0.120 & $0.59(0.29-1.17) ; 0.131$ & \\
\hline Times SP & s received $(n=161)$ & & & & & \\
\hline 1 & $45(83.3)$ & $9(16.7)$ & 5507 & 0018 & 1 & 1 \\
\hline 2 & $72(66.7)$ & $35(33.3)$ & 0.591 & 0.010 & $1.37(0.16-0.86) ; 0.021$ & $1.34(0.10-1.12) ; 0.077$ \\
\hline Syphilis t & & & & & & \\
\hline No & $1(20.0)$ & $4(80.0)$ & 0570 & 0002 & 1 & 1 \\
\hline Yes & $175(76.8)$ & $53(23.2)$ & 8.529 & 0.003 & $3.21(1.45-2.73) ; 0.022$ & $1.27(0.05-1.45) ; 0.885$ \\
\hline LLITN re & & & & & & \\
\hline No & $55(88.7)$ & $7(11.3)$ & 9245 & 0.002 & 1 & 1 \\
\hline Yes & $121(70.8)$ & $50(29.2)$ & 9.245 & 0.002 & $3.26(0.11-0.65) ; 0.004$ & $2.17(0.03-0.92) ; 0.039$ \\
\hline Counselle & & & & & & \\
\hline No & $4(40.0)$ & $6(60.0)$ & 7140 & 0.008 & 1 & 1 \\
\hline Yes & $172(77.1)$ & $51(22.9)$ & 7.140 & 0.008 & $5.06(1.37-8.62) ; 0.015$ & $3.13(0.33-1.37) ; 0.331$ \\
\hline Counselle & nutrition & & & & & \\
\hline No & $0(0.0)$ & $3(100)$ & 6.194 & 0.013 & & \\
\hline
\end{tabular}


Table 4: Continued.

\begin{tabular}{|c|c|c|c|c|c|c|}
\hline \multirow[b]{2}{*}{ Variable } & \multicolumn{2}{|c|}{ Birth weight } & \multicolumn{2}{|c|}{ Pearson $\mathrm{chi}^{2}$} & \multirow[b]{2}{*}{ COR (95\% CI); $p$ value } & \multirow[b]{2}{*}{ AOR (95\% CI); $p$ value } \\
\hline & $\begin{array}{c}\text { Normal }(2.5-4.0 \mathrm{~kg}) \\
n=176(\%)\end{array}$ & $\begin{array}{c}\text { Abnormal }(<2.5 \mathrm{~kg}) \\
n=57(\%)\end{array}$ & $\mathrm{Chi}^{2}$ & $p$ value & & \\
\hline Yes & $176(76.5)$ & $54(23.5)$ & & & Omitted & \\
\hline \multicolumn{7}{|c|}{ Birth outcome } \\
\hline Still birth & $0(0.0)$ & $2(100)$ & \multirow{2}{*}{6.229} & \multirow{2}{*}{0.013} & & \\
\hline Live birth & $176(76.2)$ & $55(23.8)$ & & & Omitted & \\
\hline \multicolumn{7}{|c|}{ Received minimum ANC service } \\
\hline No & $116(73.4)$ & $42(26.6)$ & \multirow{2}{*}{2.391} & \multirow{2}{*}{0.122} & 1 & \\
\hline Yes & $58(82.9)$ & $12(17.1)$ & & & 1.75 (0.86-3.58); 0.125 & \\
\hline
\end{tabular}

weight $(2.5-4.0 \mathrm{~kg})$ compared with those who received fewer services. This finding was not surprising, because mothers who attend ANC sessions and receive all services required and put the pieces of advice into practice have more chance of delivering healthy babies [28].

Approximately 24.5\% of babies born between June 2017 and May 2018 were below the normal birth weight $(<2.5 \mathrm{~kg})$. In contrary, the Nigerian studies and the Ethiopian study reported prevalence $(6.3 \%, 10.2 \%$, and $17.1 \%)$ of a low birth weight, which are lower than what the present study reported [29-31]. Meanwhile, low-birth-weight children are known to suffer from lack of proper physical growth and mental development, are susceptible to infections and physical handicaps, and are prone to emotional disorders [32]. About $1 \%$ of pregnancies in the Wa East District resulted in a stillbirth. This disagrees with a study carried out in the Hohoe Municipality in Ghana, which reported a high prevalence of stillbirth [33] and the study among the ethnically diverse population in the United Kingdom [34].

Religion was found to be associated with birth weight in the present study and agrees with a study in India [35], and in Africa, the tradition of selection and preference of nutritionally poor food items during pregnancy is deep-rooted in communities and may be due to religious practices that affect maternal healthcare-seeking behaviour and nutrition [36]. Again, another study has shown that maternal religious attendance has a protective effect against low birth weight [37]. Maternal marital status was also found to be associated with normal birth weight in the present study and agrees with the Nigerian studies $[29,30]$. However, mothers who are not married are known to have a higher risk of delivering lowbirth-weight children [19]. The present study also indicated that mothers who have attained higher education were more likely to give birth to babies with a normal birth weight compared with mothers who have attained lower education or did not go to school. This educational finding concurs with Tayie and Lartey's study, which reported that pregnant women with higher educational attainment turn to seek early care and that those who seek early care are likely to give birth to children with a normal birth weight $(2.5-4.0 \mathrm{~kg})$ than women with no education [38]. Meanwhile, maternal education has an influence on negative health behaviours, which in turn impact child health outcomes $[15,16]$.
Mothers who had their urine tested were found to be associated with given birth to a child with a normal birth weight, and a study has shown that mothers who had their urinary metabolites measured at the end of the first trimester are associated with an increased risk of negative birth outcomes [39]. Also, mothers who were given LLITN to help protect them from mosquitoes' bite and prevent malaria were significantly associated with a normal birth weight, with a study indicating reduce birth weight among mothers who has malaria during pregnancy [40]. These services are part of the minimum services all pregnant women were supposed to receive from ANC facilities visited. A study has shown that mothers who did not go for antenatal care and for that reason could not receive services required were associated with low birth weight and other birth outcomes [41]. All efforts should be instituted to ensure pregnant mothers receive all required services because these services are essential to ensure both the mother and child's life are saved.

\section{Conclusion}

Notwithstanding the benefits of antenatal care services, only $62.2 \%$ of pregnant women attended 4 or more ANC visits and $70 \%$ of the mothers did not receive all ANC services required. Also, $24.5 \%$ and $0.9 \%$ of pregnancies resulted in low birth weights and stillbirths, respectively. Normal birth weight is significantly associated with maternal religion, educational attainment, marital status, mothers who received long-lasting insecticide-treated nets, and those who had their urine tested. Inconsistency in logistics and medical supply to health facilities in the district should be addressed to ensure mothers who attend ANC clinics can receive all services required. Again, the rate of low-birth-weight children is very high. Therefore, there is a need for special attention from all stakeholders to reverse the trend.

5.1. Recommendations. The district health administration and other stakeholders in health should enhance education on the importance of antenatal care services including the necessity for early antenatal care and male involvement in women's health. The health authorities should institute supply-chain management systems to prevent logistics and 
medicine shortages. Again, there should be a study to ascertain the actual cause of the low birth weight in the district.

\author{
Abbreviations \\ ANC: $\quad$ Antenatal care \\ IPTp: Intermittent preventive treatment in pregnancy \\ HIV/AIDS: Human immunodeficiency virus/acquired \\ immune deficiency syndrome \\ PMTCT: Prevention of mother-to-child transmission \\ WHO: World Health Organization \\ CHPS: $\quad$ Community-based health planning and services \\ EmONC: Basic emergency obstetrics and newborn care \\ SP: $\quad$ Sulphadoxine-pyrimethamine \\ LLITN: Long-lasting insecticide-treated net \\ JHS: Junior secondary school \\ SHS: $\quad$ Senior secondary school \\ FP: $\quad$ Family planning \\ COR: $\quad$ Crude odds ratio \\ AOR: $\quad$ Adjusted odds ratio.
}

\section{Data Availability}

The data used to support the findings of this study can be made available from the corresponding author upon request.

\section{Ethical Approval}

The study protocol was reviewed and approved by the Research Ethics Committee of the Institute of Health Research (REC-IHR) in the University of Health and Allied Sciences in Ghana with a certified number UHAS-REC A-6 [54] 18-19. Also, the authority to review health records and to carry out the study in the district was sought from the Wa East District Health Directorate.

\section{Consent}

Informed consent for voluntary participation was obtained from the study subjects.

\section{Conflicts of Interest}

The authors of this work declare that they have no competing interest regarding the study and the publication of this paper.

\section{Authors' Contributions}

PKA, MB, and MA had extensive contribution to the conception and acquisition of data of this research. PKA, MB, MA, $\mathrm{SNY}, \mathrm{KO}, \mathrm{GBA}$, and SN had considerable contribution to the design, analysis data, and interpretation of the findings. All authors critically revised the paper for important intellectual contents. All authors read and approved the final manuscript.

\section{Acknowledgments}

The authors express their appreciations to the Wa East District Director of Health Service for granting us the permission to carry out the study and also to all the heads of ANC and delivery facilities within the district where the study was conducted.

\section{References}

[1] O. M. R. Campbell, W. J. Graham, and on behalf of The Lancet Maternal Survival Series steering group, "Strategies for reducing maternal mortality: getting on with what works," The Lancet, vol. 368, no. 9543, pp. 1284-1299, 2006.

[2] O. Lincetto, S. Mothebesoane-Anoh, P. Gomez, and S. Munjanja, "Antenatal care," Opportunities for Africa's newborns: Practical data, policy and programmatic support for newborn care in Africa, pp. 55-62, 2006.

[3] World Health Organization, World Bank, and United Nations Population Fund \& United Nations Children's Fund, Trends in Maternal Mortality: 1990-2015: Estimates from WHO, UNICEF, UNFPA, World Bank Group and the United Nations Population Division, World Health Organization, 2015, https:// apps.who.int/iris/handle/10665/194254.

[4] J. E. Lawn, S. Cousens, J. Zupan, and for the Lancet Neonatal Survival Steering Team, "4 million neonatal deaths: when? Where? Why?” The Lancet, vol. 365, no. 9462, pp. 891-900, 2005.

[5] World Health Organization, Tracking Universal Health Coverage: First Global Monitoring Report, World Health Organization, 2015, https://www.who.int/health_financing/ documents/tracking-uhc/en/.

[6] World Health Organization, World Health Statistics 2016: Monitoring Health for the SDGs Sustainable Development Goals, World Health Organization, 2016, https://www.who .int/gho/publications/world_health_statistics/2016/en/.

[7] Unicef, "Committing to child survival: a promise renewed," 2014, http://files.unicef.org/publications/files/APR_2014_ web_15Sept14.pdf.

[8] Ghana Statistical Service (GSS), Ghana Health Service (GHS), and ICF, Ghana maternal health survey 2017: key findings, GSS, GHS, and ICF, Rockville, MD, USA, 2018.

[9] Ghana Statistical Service (GSS), Ghana Health Service (GHS), and ICF International, Ghana demographic and health survey 2014, GSS, GHS, and ICF International, Rockville, MD, USA, 2015.

[10] GHS Annual Report, "Ghana Health Service: Wa East Annual Report,” 2019, unpublished.

[11] E. F. C. Murta, G. C. Freire, D. C. Fabri, and R. H. Fabri, "Could elective cesarean sections influence the birth weight of full-term infants?," Sao Paulo Medical Journal, vol. 124, no. 6, pp. 313-315, 2006.

[12] G. W. Snedecor and W. G. Cochran, Statistical Methods, Iowa State Univ. Press Iowa, Ames, 8th edition, 1989.

[13] I. K. Ndu, B. O. Edelu, S. N. Uwaezuoke et al., "Maternal risk factors associated with low birth weight neonates: a multi-centre, cross-sectional study in a developing country," Journal of Neonatal Biology, vol. 101, 2015.

[14] H. Cammu, G. Martens, and M. J. N. C. Keirse, "Mothers' level of education and childbirth interventions: a population-based study in Flanders, Northern Belgium," Birth, vol. 38, no. 3, pp. 191-199, 2011.

[15] P. M. Güneş, “The role of maternal education in child health: evidence from a compulsory schooling law," Economics of Education Review, vol. 47, pp. 1-16, 2015. 
[16] H. Jürges, S. Reinhold, and M. Salm, "Does schooling affect health behavior? Evidence from the educational expansion in Western Germany," Economics of Education Review, vol. 30, no. 5, pp. 862-872, 2011.

[17] J. D. Meyer, N. Warren, and S. Reisine, "Racial and ethnic disparities in low birth weight delivery associated with maternal occupational characteristics," American Journal of Industrial Medicine, vol. 53, no. 2, pp. 153-162, 2010.

[18] O. A. Kehinde, O. F. Njokanma, and D. M. Olanrewaju, "Parental socioeconomic status and birth weight distribution of Nigerian term newborn babies," Nigerian Journal of Paediatrics, vol. 40, no. 3, pp. 299-302, 2013.

[19] P. S. Shah, J. Zao, and S. Ali, "Maternal marital status and birth outcomes: a systematic review and meta-analyses," Maternal and Child Health Journal, vol. 15, no. 7, pp. 1097-1109, 2011.

[20] S. MacLeod and J. L. Kiely, "The effects of maternal age and parity on birthweight: a population-based study in New York City," International Journal of Gynecology \& Obstetrics, vol. 26, no. 1, pp. 11-19, 1988.

[21] WHO Reproductive Health Library, "WHO recommendation on group antenatal care," in The WHO reproductive health library, World Health Organization, Geneva, 2016, https:// extranet.who.int/rhl/topics/improving-health-system-perfor mance/implementation-strategies/who-recommendationgroup-antenatal-care.

[22] GHS, "Ghana Health Service guidelines for performance review and reporting by Budget and Management Centers 2016-2019," 2016, unpublished.

[23] T. Dahiru and O. M. Oche, "Determinants of antenatal care, institutional delivery and postnatal care services utilization in Nigeria," Pan African Medical Journal, vol. 21, no. 1, 2015.

[24] A. A. A. Ali, M. M. Osman, A. O. Abbaker, and I. Adam, "Use of antenatal care services in Kassala, eastern Sudan," BMC Pregnancy and Childbirth, vol. 10, no. 1, p. 67, 2010.

[25] N. N. Asundep, A. P. Carson, C. A. Turpin et al., "Determinants of access to antenatal care and birth outcomes in Kumasi, Ghana," Journal of Epidemiology and Global Health, vol. 3, no. 4, pp. 279-288, 2013.

[26] M. Saaka, K. Emmanuel, and I. Farruza, Adequacy of prenatal care utilization and its effect on postpartum infant feeding behaviors in Northern Ghana, SciMedCentral, 2016, http:// hdl.handle.net/123456789/1403.

[27] M. M. Islam and M. S. Masud, "Determinants of frequency and contents of antenatal care visits in Bangladesh: assessing the extent of compliance with the WHO recommendations," PLoS One, vol. 13, no. 9, article e0204752, 2018.

[28] H. Zhou, A. Wang, X. Huang et al., "Quality antenatal care protects against low birth weight in 42 poor counties of Western China," PloS one, vol. 14, no. 1, article e0210393, 2019.

[29] H. B. Oladeinde, O. B. Oladeinde, R. Omoregie, and A. A. Onifade, "Prevalence and determinants of low birth weight: the situation in a traditional birth home in Benin City, Nigeria," African Health Sciences, vol. 15, no. 4, pp. 1123-1129, 2016.

[30] B. O. Olusanya and G. E. Ofovwe, "Predictors of preterm births and low birthweight in an inner-city hospital in subSaharan Africa," Maternal and Child Health Journal, vol. 14, no. 6, pp. 978-986, 2010.

[31] B. M. Zeleke, M. Zelalem, and N. Mohammed, "Incidence and correlates of low birth weight at a referral hospital in Northwest Ethiopia," Pan African Medical Journal, vol. 12, no. 1, 2012.
[32] C. M. Drillien, "Growth and development in a group of children of very low birth weight," Archives of Disease in Childhood, vol. 33, no. 167, pp. 10-18, 1958.

[33] F. Agbozo, A. Abubakari, J. Der, and A. Jahn, "Prevalence of low birth weight, macrosomia and stillbirth and their relationship to associated maternal risk factors in Hohoe Municipality, Ghana," Midwifery, vol. 40, pp. 200-206, 2016.

[34] N. Penn, E. Oteng-Ntim, and P. Doyle, "PPO. 34 The role of ethnicity in determining the prevalence of stillbirth in an ethnically-diverse UK population," Archives of Disease in Childhood-Fetal and Neonatal Edition, vol. 99, article A161, Supplement 1, 2014.

[35] P. S. Thomre, A. L. Borle, J. D. Naik, and S. S. Rajderkar, "Maternal risk factors determining birth weight of newborns: a tertiary care hospital based study," International Journal of Recent Trends in Science and Technology, vol. 5, no. 1, pp. 38, 2012.

[36] M. Gebremedhin, F. Ambaw, E. Admassu, and H. Berhane, "Maternal associated factors of low birth weight: a hospital based cross-sectional mixed study in Tigray, Northern Ethiopia," BMC Pregnancy and Childbirth, vol. 15, no. 1, p. 222, 2015.

[37] A. M. Burdette, J. Weeks, T. D. Hill, and I. W. Eberstein, "Maternal religious attendance and low birth weight," Social Science \& Medicine, vol. 74, no. 12, pp. 1961-1967, 2012.

[38] F. A. Tayie and A. Lartey, "Antenatal care and pregnancy outcome in Ghana, the importance of women \'s education," African Journal of Food, Agriculture, Nutrition and Development, vol. 8, no. 3, pp. 291-303, 2008.

[39] L. Maitre, E. Fthenou, T. Athersuch et al., "Urinary metabolic profiles in early pregnancy are associated with preterm birth and fetal growth restriction in the Rhea mother-child cohort study," BMC Medicine, vol. 12, no. 1, p. 110, 2014.

[40] P. De Beaudrap, E. Turyakira, L. J. White et al., "Impact of malaria during pregnancy on pregnancy outcomes in a Ugandan prospectivecohort with intensive malaria screening and prompt treatment," Malaria Journal, vol. 12, no. 1, p. 139, 2013.

[41] N. Assefa, Y. Berhane, and A. Worku, "Wealth status, mid upper arm circumference (MUAC) and antenatal care (ANC) are determinants for low birth weight in Kersa, Ethiopia," PLoS One, vol. 7, no. 6, article e39957, 2012. 